\title{
Synthesis of the reversed stationary phase for solid phase extraction using trimethoxyoctadecyl silane
}

- Nguyen Tien Giang

- Nguyen Huy Du

- Nguyen Anh Mai

University of Science, VNU-HCM

(Received on July $20^{\text {th }} 2015$, accepted on March $31^{\text {th }}$ 2016)

\begin{abstract}
Octadecyl grafting silica was synthesized using trimethoxyoctadecyl silane. Reaction conditions were optimized so that the carbon percentage of resulted material was similar to that of commercial products. Temperature and catalyst played very important roles in the reaction. The material was also undergone the end-capping process to reduce unreacted silanol
\end{abstract} Key words: reversed stationary phase, octadecyl modified silica, alkoxysilane, solid phase extraction

\section{INTRODUCTION}

Solid phase extraction (SPE) is a well-established sample pretreatment technique because it demands less organic solvents and can remove interferences simultaneously. In SPE chemical structure of sorbent materials play a decisive role[1]. Currently, the most popular sorbent material is conventional reversed phase (CRP) on silica support.

CRP is synthesized by directly bonding alkoxyoctadecyl silane or chlorooctadecyl silane onto silica surface[2-5]. While chlorolsilane is very reactive, alkoxysilane is one of the least reactive reagents[3]. However, during the reaction with silica, chlorosilane produces $\mathrm{HCl}$ by-product which can damage the main product. For alkoxysilane, the byproduct is alcohol which is harmless and easy to remove in distilled conditions. Besides, the less reactivity of alkoxysilane can be overcome by employing an appropriate catalyst [6]. groups. Final product owned $14.1 \%$ of carbon content and $75 \%$ of the unreacted silanols. Retention behavior of product was tested and compared to the same noes available on the market. Results showed that both resulted material and commercial had the same retention properties.

In the current study, CRP sorbent was synthesized using alkoxyoctadecyl silane and its retention properties were compared with commercial CRPs.

\section{MATERIAL AND METHODS}

\section{Marterials}

Silica (particle diameter $40-60 \mu \mathrm{m}$, mean pore diameter $60 \AA$, specific surface area $500 \mathrm{~m}^{2} / \mathrm{g}$, were purchased from Scharlau. Trimethoxyoctadecyl silane (TMOS) $90 \%$ and Chlorotrimethyl silane (97\%) was product of Sigma-Aldrich.

Imidazole, $p$-toluenesulfonic acid, pyridine, formic acid were products of Merck, diethylamine, toluene, acetonitrile for HPLC were purchased from Labscan. Five analytes consist of caffeine, sulfadimethoxine, bromacil, warfarin, prednisone were obtained from Sigma-Aldrich. 


\section{Preparation of CRP}

Silica gel was dried at $200{ }^{\circ} \mathrm{C}$ for $24 \mathrm{~h}$. After cooling to room temperature, $2 \mathrm{~g}$ of silica were added to a flask, then $20 \mathrm{~mL}$ of toluene, $0.5 \mathrm{~mL}$ of TMOS and $150 \mathrm{mg} p$-toluenesulfonic aicd were added. The mixture was heated to $100{ }^{\circ} \mathrm{C}$ under reflux and paddle stirred condition for $4 \mathrm{~h}$. The product was filtered and washed three times successively with $30 \mathrm{~mL}$ portions of toluene, diethylether, methanol, acetone and finally dried at $50{ }^{\circ} \mathrm{C}$ for $2 \mathrm{~h}$.<smiles>CCCCCC[Si]O[Si](O)(CCCC)CCCC</smiles>

Fig. 1. Reaction of silica and trimethoxyoctadecyl silane

\section{End-capping of CRP}

To a $100 \mathrm{~mL}$ flask, add $1 \mathrm{~g}$ of CRP, $15 \mathrm{~mL}$ of toluene, $1 \mathrm{~mL}$ of chlorotrimethyl silane and $0.5 \mathrm{~g}$ of imidazole. The mixture was heated to $80{ }^{\circ} \mathrm{C}$ under reflux and paddle stirred condition for $4 \mathrm{~h}$. The final product was filtered and washed three times successively with $30 \mathrm{~mL}$ portions of toluene, methanol, acetone and finally dried at $50{ }^{\circ} \mathrm{C}$ for $2 \mathrm{~h}$.

\section{Sorbent material characterizations}

The carbon content was analyzed by Alison wetoxidizing method [7]. Briefly, amixture of $\mathrm{K}_{2} \mathrm{CrO}_{7}$
$(4 \mathrm{~g}), \mathrm{H}_{2} \mathrm{SO}_{4}$ (concd) $: \mathrm{H}_{3} \mathrm{PO}_{4}$ (concd) $\left.(3: 2, \mathrm{v} / \mathrm{v})\right)(30 \mathrm{~mL})$ were used to oxidize the sorbent material $(0.3 \mathrm{~g})$ at high temperature (approximately $200{ }^{\circ} \mathrm{C}$ ) and produce $\mathrm{CO}_{2}$. The resulted $\mathrm{CO}_{2}$ was absorbed to $20 \mathrm{~mL}$ of $0.25 \mathrm{~N} \mathrm{NaOH}$ solution. Blank sample was also performed by substituting silica for sorbent material. By titrating the $\mathrm{NaOH}$ solutions of blank and material samples with $\mathrm{HCl} 0.25 \mathrm{~N}$ and phenolphthalein as indicator, carbon content can be calculated as the following formula:

$$
\mathrm{C}(\%)=\frac{\left(\mathrm{V}_{\mathrm{B} 1}-\mathrm{V}_{\mathrm{S}}\right) \times \mathrm{C}_{\mathrm{HCl}} \times 12}{\mathrm{~m}(\mathrm{~g}) \times 10}
$$

$\mathrm{V}_{\mathrm{Bl}}$ : Volume of $\mathrm{HCl}$ solution to titrate absorption solution of blank sample (mL)

$\mathrm{V}_{\mathrm{S}}$ : Volume of $\mathrm{HCl}$ solution to titrate absorption solution of sample (mL)

$\mathrm{C}_{\mathrm{HCl}}$ : Concentration of $\mathrm{HCl}$ solution $(\mathrm{M})$

$\mathrm{m}$ : Weight of sample $(\mathrm{g})$ 
Table 1. Base-acid characteristics of five standards used for testing retention of amide-RP

\begin{tabular}{|l|c|c|}
\hline Compound & Class & Log P \\
\hline Caffeine & Base & -0.13 \\
\hline Sulfadimethoxin & Acid & 1.48 \\
\hline Predneson & Neutral & 1.57 \\
\hline Bromacil & Base & 2.1 \\
\hline Warfarin & Acid & 3.42 \\
\hline
\end{tabular}

\section{Evaluation of retention}

To evaluate retention properties of resulted CRP, five analytes with different chemical properties were used (Table 1). The mixture of the five compounds $(10 \mu \mathrm{g} / \mathrm{mL})$ in water were loaded onto the homemade amide-RP cartridges and other three commercial C18 cartridges (Agilent SampliQ C18, Strata C18-E and Isolute C18), the bounded analytes were then eluted with $5 \mathrm{~mL}$ mixture of methanol and water. The collected eluents were analyzed by HPLC to calculate the recoveries.

\section{Chromatography conditions}

HPLC separations were performed with Agilent 1100 system, UV detector, AscentisTM C18 Supelco separation column $(25 \mathrm{~cm} \times 4.6 \mathrm{~mm}, 5 \mu \mathrm{m})$. Detection wavelength was of $254 \mathrm{~nm}$, temperature of $40{ }^{\circ} \mathrm{C}$. Aqueous $0.1 \%$ formic acid (phase A) and acetonitrile $0.1 \%$ formic acid (phase B) were used as mobile phase at $1 \mathrm{~mL} \cdot \mathrm{min}^{-1}$. The mobile phase gradient

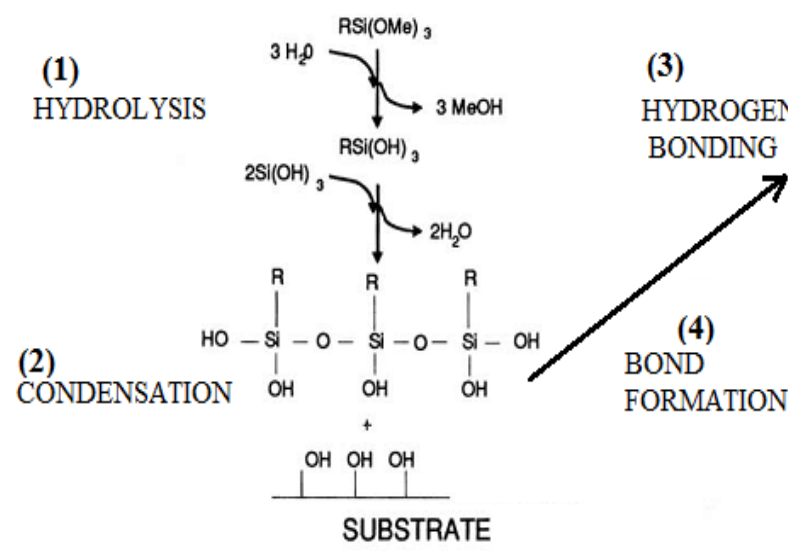

program was started with $15 \%$ of phase $\mathrm{B}$, increased to $40 \%$ phase B for $14 \mathrm{~min}$ and to $100 \%$ for $22 \mathrm{~min}$.

\section{RESULTS AND DISCUSSION}

\section{Synthesis conditions for CRP}

\section{Effect of catalyst}

Catalyst is a very important element in silanization. Reaction of octadecyltrimethoxy silane and silica gave only $3.5 \%$ in carbon content without catalyst. The reaction of surface silanols with alkoxysilanes can be catalyzed by either acids or bases [6]. As the mechanism showed in figure 2, before removing water to form the linkage to silica surfaces at high temperature, the alkoxy groups of alkoxysilanes are hydrolyzed to form intermediate silanols which are very reactive. Catalyst accelerates the hydrolysis (1) and condensation (2).

Fig. 2. Reaction mechanism of alkoxysilane and silanol. 
Table 2. Properties of some organic acids and bases.

\begin{tabular}{|l|c|c|c|}
\hline Catalyst & $\mathrm{p} K_{\mathrm{b}}$ & $\mathrm{p} K_{\mathrm{a}}$ & $\mathrm{B}_{\mathrm{p}}\left({ }^{\circ} \mathbf{C}\right)$ \\
\hline Pyridine & $\mathbf{8 . 7}$ & - & $\mathbf{1 1 5 . 2}$ \\
\hline Triethylamine & $\mathbf{3 . 2}$ & - & $\mathbf{8 8 . 6}$ \\
\hline Diethylamine & $\mathbf{3 . 1}$ & - & $\mathbf{5 5 . 5}$ \\
\hline Imidazole & $\mathbf{7 . 0}$ & - & $\mathbf{2 5 6}$ \\
\hline $\begin{array}{l}p \text {-toluene } \\
\text { sulfonic acid }\end{array}$ & - & $\mathbf{- 2 . 8}$ & $\mathbf{1 4 0}$ \\
\hline
\end{tabular}

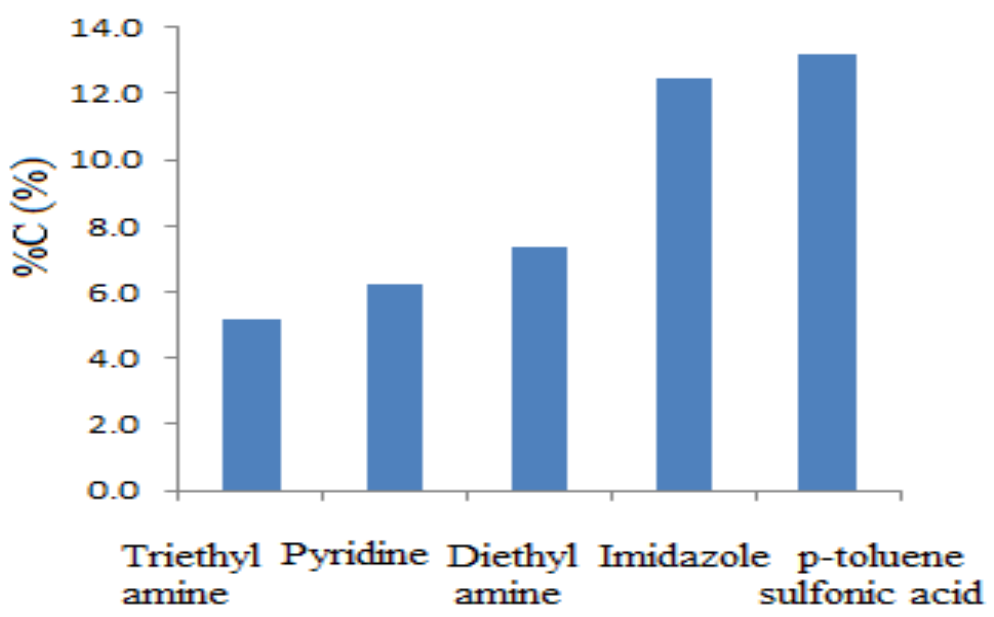

Fig. 3. Effect of catalyst on reaction of silica and trimethoxyoctadecyl silane

Fig 3 shows that bases as triethylamine, pyridine and diethylamine had weak effect on the silanization, and the carbon content of the obtained product was from 6 to $8 \%$. This could be due to their weak basic property and low boiling point (Table 2). Imidazole was a bether catalyst with $12.5 \%$ in carbon amount. However, the best was $p$-toluenesulfonic acid with
$13.2 \%$ of carbon loading, corresponding to the reaction yield of $90 \%$. This was similar to results of the previous publication [6]. As a result, ptoluenesulfonic acid was selected for subsequent investigations.

Effect of amount of catalyst 


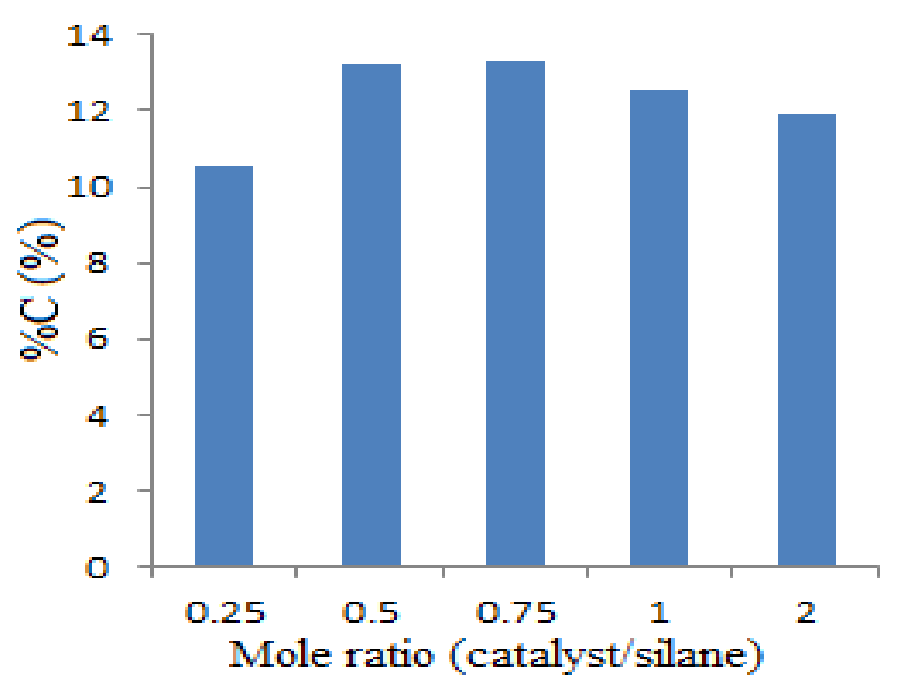

Fig. 4. Effect of catalyst amount on reaction of silica and trimethoxyoctadecyl silane

As can be seen from Fig. 4, good yield (90\%, corresponding to $\% \mathrm{C}$ of $13.2 \%$ ) was obtained when the number of moles of $p$-toluenesulfonic acid was a half compared to that of silane. Consequently the mole ratio of 0.5 was selected for the following investigations.
As can be seen from step 4 of silanization mechanism (Fig. 2), the temperature is a very essential factor and need to be optimized. Besides, solvent also needs to be investigated because it affects the solubility of the reagent and the permeability of silica.

\section{Effect of solvent and temperature}

Table 3. Properties of some solvents

\begin{tabular}{|c|c|c|c|c|}
\hline Solvent & Xylene & Toluene & 1,2-dichlorobenzene & Benzene \\
\hline $\mathrm{B}_{\mathrm{p}}\left({ }^{\circ} \mathrm{C}\right)$ & 138.5 & 110 & 180 & 80 \\
\hline Dipole moment (D) & $0.07-0.64$ & 0.39 & 1.80 & 0 \\
\hline
\end{tabular}




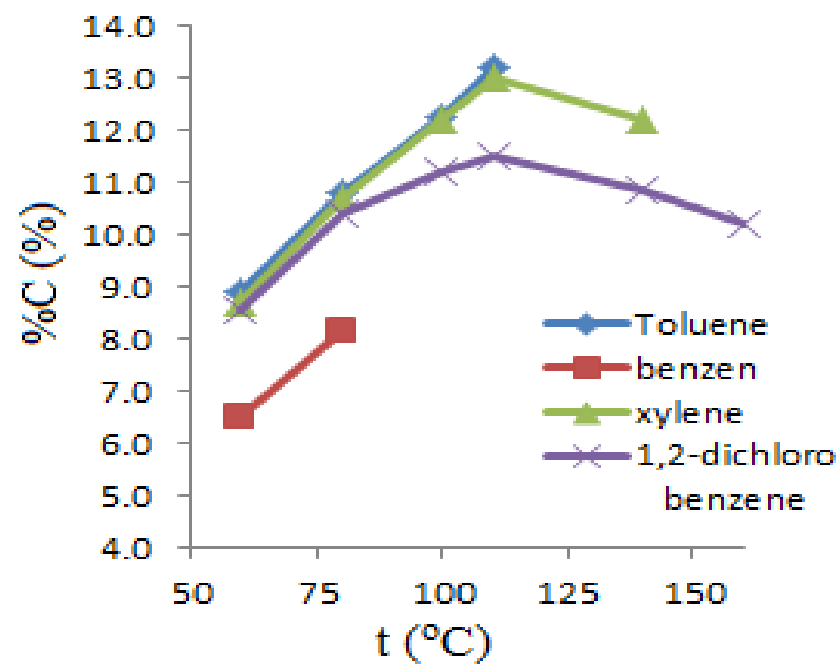

Fig. 5. Effect of temperature and solvent on reaction of silica and trimethoxyoctadecyl silane

Fig. 5 shows that the carbon percentage of CRP raises as the reaction temperature increases. However, solvents possessing too low or high polarity such as benzene or 1,2-dichlorobenzene gave low reaction yield. Toluene and xylene had the same trend at temperature lower, than $110{ }^{\circ} \mathrm{C}$, and highest carbon amount of product with these solventsreach up to $13.2 \%$. Since toluene is less toxic than xylene, it was consequently chosen for subsequent experiments.

Effect of reaction time

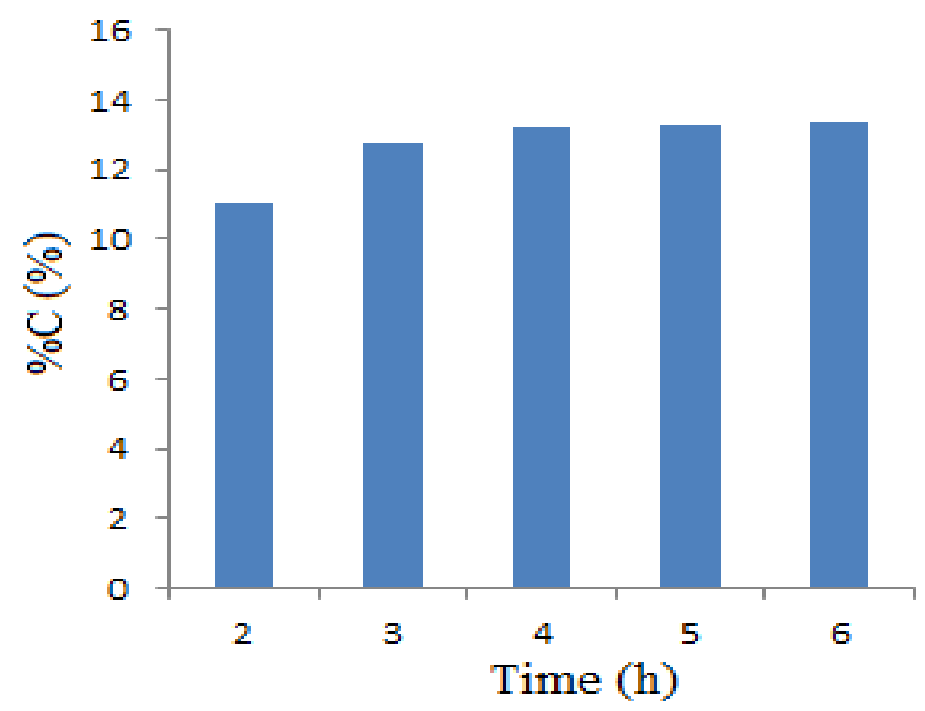

Fig. 6. Effect of time on reaction of silica and trimethoxyoctadecyl silane

\section{Trang 16}


Fig. 6 shows that the reaction of octadecyltrimethoxy silane and silica happened very fast at the first two hours and then gradually slow down. After 4 hours the carbon loading almost reached the maximum with of $13.2 \%$. As a result, the reaction should be carried out for $4 \mathrm{~h}$.

\section{End-capping}

The surface coverage of silica with octadecyl silane could not have high density due to steric hindrance. In an effort to reduce unreacted silanol groups, significantly smaller silanes were used, socalled end-capping process [8, 9]. In this current work, the end-capping process was conducted as in Patent EP1361915 B1 with chlorotrimethyl silane without further investigations. Table 4 shows that after the end-capping process completed, a slight increase of the carbon content of CRP (14.1) was observed.

Table 4. Properties of resulted material before and after end-capping process

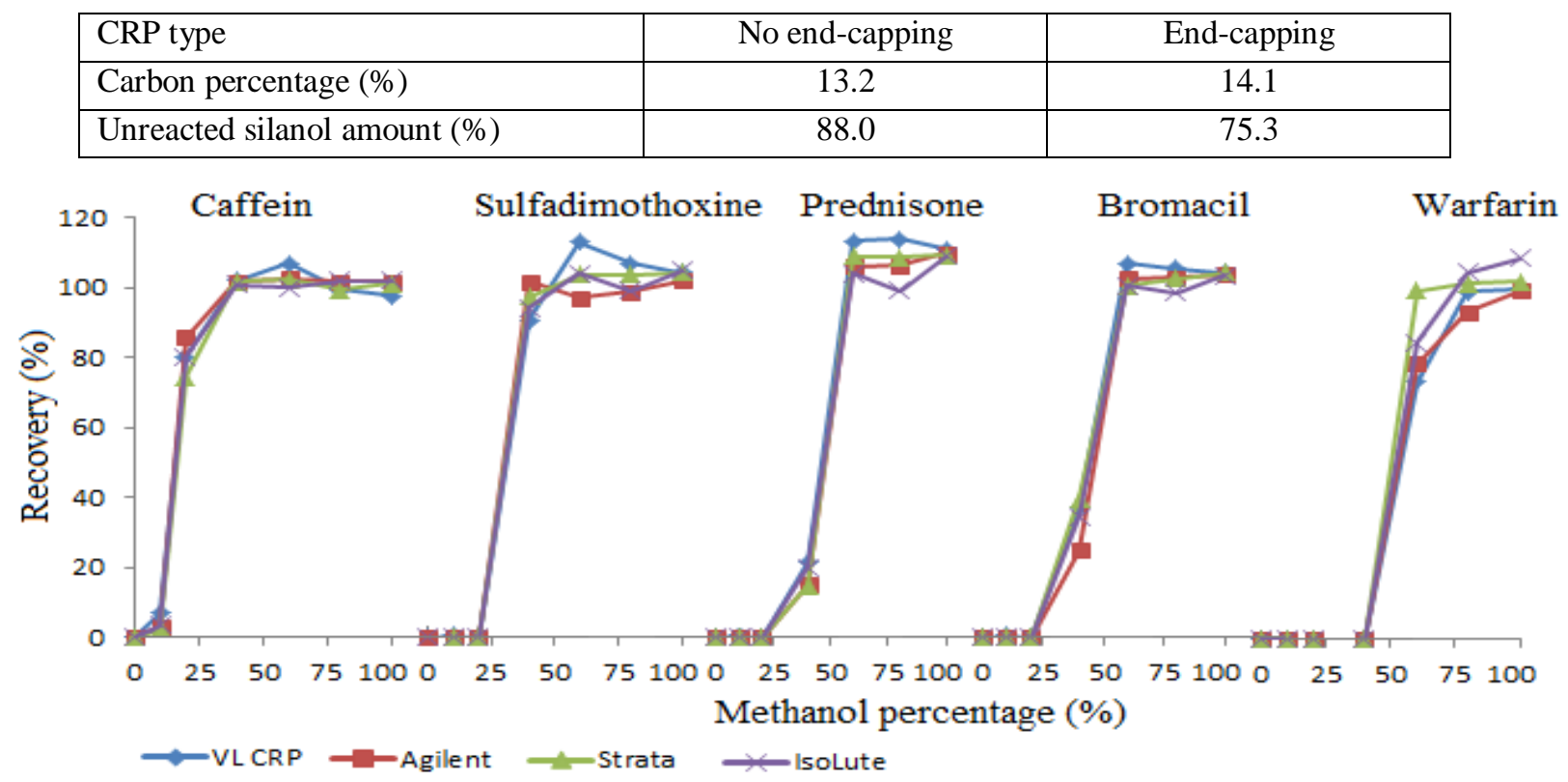

Fig. 7. Elution profiles of tested analytes with resulted material and three commercial CRPs sorbents.

\section{Retention behavior}

The five analytes with different aeidic or basi properties (Table 1) were used in testing the retention behavior of the CRP sorbent in comparison to the commercial C18 sorbents.

Elution profiles show that resulted CRP had similar retention behavior as the three other commercial CRPs for all acid and base compounds. Therefore, the ability of purifying and concentrating analytes of resulted CRP were the same as the others.

\section{CONCLUSION}

Octadecyl modified silica was synthesized using trialkoxyoctadecyl silane reagent. The of reaction yield between silica and the silane reagent largely depended on the temperature and catalysts. Resulted material was end-capped and possessed $14.1 \%$ of the carbon content. The retention behaving of the oltained product was similar to those of the same commercial products. Therefore, it was able to purify and concentrate analytes as much as other available product. 


\section{Tổng hợp vật liệu pha đảo dùng trong chiết pha rắn với tác chất trimethoxyoctadecyl silane}

- Nguyễn Tiến Giang

- Nguyễn Huy Du

- Nguyễn Ánh Mai

Trường Đại học Khoa học Tự nhiên, ĐHQG-HCM

\section{TÓM TẮT}

Vật liệu pha đảo trên nền silica được tổng hợp với tác chất trimethoxyoctadecyl silane. Các điều kiện phản úng được tối uu sao cho sản phẩm tạo ra có hàm luợng carbon đạt trong khoảng trung bình so với sản phẩm thuoong mại cùng loại. Kết quả cho thấy phản ứng giữa các nhóm silanol bề mặt và tác chất silane phu thuộc rất nhiều vào nhiệt độ và xúc tác.

Quá trình end-capping cũng được áp dụng để loại bớt các nhóm silanol còn lại trên bề mặt silica. Vật liệu tư tổng hơp có phần trăm carbon là $14,1 \%$ và khoảng $75 \%$ các nhóm silanol chua phản úng. Đặc tính lư giũ của sản phẩm được so sánh với các sản phẩm thuoong mại trên thị truờng và kết quả cho thấy chúng cho kết quả tương tụ.

Tù khóa: chiết pha rắn, SPE pha đảo, silica, trialkoxyoctadecyl silane

\section{TÀI LIỆU THAM KHẢO}

[1]. D. Luo, Q.W. Yu, H.R. Yin, Y.Q. Feng, Humic acid-bonded silica as a novel sorbent for solidphase extraction of benzo [a] pyrene in edible oils, Analytica Chimica Acta, 588, 261-267 (2007).

[2]. K.A. Lippa, L.C. Sander, R.D. Mountain, molecular dynamics simulations of alkylsilane stationary-phase order and disorder. 1. Effects of Surface Coverage and Bonding Chemistry, Anal Chem, 77, 7852-7861 (2005).

[3]. J.N. Kinkel, K.K. Unger, Role of solvent and base in the silanization reaction of silicas for reversed-phase high-performance liquid chromatography, Journal of Chromatography A, 316, 193-200 (1984).

[4]. M. Hetem, J. de Haan, H. Claessens, P. Mussche, C. Cramers, Effect of acid pretreatment of the silica substrate on the stability of octadecyl modified reversed phases, Chromatographia, 29, 473-481 (1990).

[5]. B. Buszewski, L. Nondek, A. Jurášek, D. Berek, Preparation of silanized silica with high ligand density. The effect of silane structure, Chromatographia, 23 442-446 (1987).

[6]. H. Engelhardt, P. Orth, Alkoxy silanes for the preparation of silica based stationary phases with bonded polar functional groups, Journal of Liquid Chromatography, 10, 1999-2022 (1987).

[7]. A.L.P.R.H.M.D.R. Keeney, Methods of soil analysis (1982).

[8]. M.L. Hair, W. Hertl, Reaction of hexamethyldisilazane with silica, The Journal of Physical Chemistry, 75, 2181-2185 (1971).

[9]. Y. Sudo, Optimization of end-capping of octadecyl-silylated silica gels by hightemperature silylation, Journal of Chromatography A, 757, 21-28 (1997). 